\title{
STUDI PEKERJAAN PASANGAN BATA BERDASARKAN PRODUKTIVITAS JUMLAH TENAGA KERJA DENGAN METODE WORK STUDY
}

\author{
Nico Hartono ${ }^{1}$, M. Hamzah Hasyim² ${ }^{2}$ Saifoe El Unas ${ }^{2}$ \\ ${ }^{1}$ Mahasiswa / Program Studi Sarjana Teknik Sipil Fakultas Teknik / Universitas Brawijaya \\ ${ }^{2}$ Dosen / Jurusan Teknik Sipil Fakultas Teknik / Universitas Brawijaya
}

\begin{abstract}
Research on the comparative analysis of masonry unit price based on SNI and Work Study was conducted by the method of analysis SNI and analysis Work Research Study. The object of this study is a simple home construction project in Nurasa Regency Nganjuk. Calculation method using the coefficient existing SNI SNI Work Study while the calculation using the coefficient obtained through the research and the results shown in the method Work Study. After processing, the results obtained in the development. the method used is the analysis of ISO 6897-2008 with the number 6.9 to work $1 \mathrm{~m} 2$ couple red brick wall size $(5 \times 11 \times 22) 1 / 2 \mathrm{~cm}$ thick brick, a mixture of species 1 PC: 4 PP. In the implementation of a method of the materials used are ISO methods but to the number of workers and working time adjusted to the field conditions where there may be differences between SNI and the field. The method of implementation in current research project is not in accordance with the SNI, because at the time of the field research used several different work groups. This certainly affects the cost of the implementation, where the number of different artisan or worker resulted in considerable cost difference anyway. In addition some of the things that makes the price to be much different and are beyond boundary problem should be eliminated in order to get the correct result - really can be compared with the SNI. Some things are omitted or overlooked include job preparation, work benangan, foreman, and the foreman. Budget plan masonry work per square meter according to SNI is USD 86,472.50. Budget plans masonry work costs per square meter with a method Work Study is USD 77,395.50. So the comparison difference masonry work cost per square meter between SNI and methods Work Study is Rp $9,076.50$.
\end{abstract}

Keywords: masonry work, unit price, SNI, work study

\section{PENDAHULUAN}

Proyek adalah suatu rangkaian kegiatan yang dikerjakan dalam waktu terbatas yang mana menggunakan sumber daya tertentu dalam rangka memperoleh suatu hasil yang terbaik pada waktu yang akan datang. Sumber daya adalah salah satu faktor penentu dalam keberhasilan suatu proyek konstruksi. Sumber daya dalam proyek berupa tenaga kerja, mesin, bahan alam, uang, dan metode pengerjaan. Tenaga kerja merupakan sumber daya yang penting dimana kualitas dan kuantitas tenaga kerja harus sesuai dengan kebutuhan perusahaan, upaya efektif dan efisien menunjang tercapainya tujuan [6].

Salah satu pekerjaan pada proyek konstruksi yang mempunyai volume pekerjaan dan jumlah tenaga kerja yang cukup besar adalah pekerjaan dinding atau pasangan bata. Dengan volume dan jumlah tenaga kerja yang besar tentu diperlukan biaya yang cukup besar pula untuk menyelesaikannya, maka produktifitas tenaga kerja harus dimaksimalkan guna meminimalisasi anggaran dan waktu penyelesaian proyek. Tjutju Yuniarsih \& Suwanto mengemukakan bahwa produktivitas kerja diartikan sebagai hasil kongkrit (produk) yang dihasilkan oleh individu atau kelompok, selama satuan waktu tertentu dalam suatu proses kerja [2]. Beberapa perihal yang dapat menghambat produktifitas tenaga kerja adalah menganggur, merokok, makan, berbincang-bincang, atau istirahat yang dilaksanakan pada jam kerja. Selain itu, ada pula variabel lain yang mempengaruhi produktifitas pekerja antara lain adalah usia kerja, motivasi kerja, pengalaman kerja [3]. Berdasarkan pada penelitian yang dilakukan Subarjo [1], tingkat pendidikan tidak berpengaruh secara parsial terhadap produktivitas karyawan karena karyawan perusahaan menilai bahwa tingkat pendidikan dianggap belum tentu menjamin meningkatnya produktivitas karyawan. 
Dalam pengukuran efektifitas jumlah pekerja terdapat banyak metode yang bisa digunakan, salah satunya work study. Work study merupakan suatu teknik yang mencakup analisis dan waktu kerja dalam suatu pekerjaan. Work Study mempunyai dua aspek utama, yaitu Method study dan Work Measurement, yang mana keduanya sangat berhubungan. Method Study digunakan untuk mengumpulkan informasi yang mana akan mendukung dalam pengambilan keputusan yg ditujukan untuk digunakan dalam membuat analisis yang sistematis akan masalah yang ada. Sedangkan Work Measurement digunakan untuk menentukan waktu yang dibutuhkan untuk pekerja yg terkualifikasi dalam suatu pekerjaan tertentu dan menghilangkan faktor-faktor yang membuat pekerjaan menjadi tidak efektif. Aplikasi metode work study dilakukan di beberapa pekerjaan / proyek dan dapat memberikan penedekatan manajemen yang cukup baik dalam hal produktivitas kerja [4][5].

Untuk mengetahui efektifitas dalam penggunaan metode work study dalam suatu pekerjaan, maka dalam penelitian ini dilakukan analisis produtifitas kinerja dengan metode work study pada proyek perumahan Nurasa Regency Nganjuk Jawa Timur yang difokuskan pada pekerjaan pasangan bata.

\section{METODE PENELITIAN}

Metode penelitian yang digunakan dalam penelitian ini adalah metode work study, yaitu penelitian dengan mengumpulkan data langsung dari pengamatan di lapangan. Studi ini dilakukan dengan mengumpulkan data primer yang diteliti langsung di lapangan dan literature yang berkaitan dengan penelitian yang dilakukan sebagai data sekunder.

\subsection{Lokasi dan Waktu Penelitian}

Objek yang akan diteliti sebagai sumber data dalam penelitian ini adalah tukang yang bekerja pada pekerjaan pasangan bata sebagai variabel terikat, yaitu mengenai faktor-faktor yang mempengaruhi kinerja sumber daya manusia di lapangan khususnya mengenai keahlian, kecepatan, dan ketepatan kerja. Pengamatan dilakukan per meter persegi pasangan bata pada masing- masing kelompok pada 1 hari kerja, sedangkan pencatatan data dilakukan per hari selama 7 hari kerja. Pengamatan dilakukan pada pukul 08.00 WIB, 10.00 WIB, dan 15.00 WIB. Tidak menutup kemungkinan penelitian ini dilakukan pada jam kerja lembur, misalnya hari Sabtu dan Minggu atau di atas jam kerja yang tertera.

\subsection{Tahap dan Prosedur Penelitian}

Tahap dan prosedur penelitian dilakukan secara sistematis. Adapun tahap dan prosedur penelitian yang akan dilakukan adalah sebagai berikut :
1.Tahap Persiapan.
2.Survei Lapangan.
3.Pengumpulan Data.
4.Penelitian atau Scoring Data.
5.Pembahasan.

\subsection{Teknik Pengumpulan Data}

Menurut Pengamatan yang dilakukan, pemasangan dinding bata untuk sebuah rumah tipe 45 dengan luasan dinding 124,55 $\mathrm{M}^{2}$ yang dikerjakan oleh 5 orang tukang, maka pekerjaan akan dapat diselesaikan dalam waktu kurang lebih 10 hari kerja. Berdasarkan waktu kerja tersebut, maka dimisalkan data sebanyak 7 hari kerja atau $70 \%$, memakai proporsi binomunal maka dapat dihitung dengan rumus sampel penelitian Cross-Sectional.

\section{PEMBAHASAN}

Data di lapangan diolah dengan cara membuat Chart yang akan menjadi acuan untuk membuat Flow Diagram dan String Diagram. Chart Pekerjaan dibuat dengan menentukan langkah - langkah yang akan diambil oleh para pekerja dalam rangka menyelesaikan pekerjaan pasangan bata. Setelah langkah - langkah pekerja diketahui maka dapat digambarkan pada Flow Diagram dengan dilengkapi gambar lokasi. Dengan melihat Flow Diagram dapat diketahui langkah - langkah aktual pekerja sesuai gambaran lokasi di lapangan.

Gambaran aktual langkah - langkah para pekerja di lapangan akan menjadi acuan pergerakan bahan atau material. Pergerakan material atau bahan ini disebut String Diagram. String diagram dibuat berbentuk garis - garis untuk membedakan alur pekerja dan alur material. Alur material ini tidak memakai penomoran dan hampir sama persis dengan alur pergerakan pekerja. Hal tersebut dikarenakan pekerja yang biasanya bergerak dengan membawa material atau bahan.

Setelah diketahui alur pergerakan pekerja dan bahan, selanjutnya kita dapat menentukan alur yang baru. Flow Diagram dan String Diagram yang baru dibuat untuk 
mencari solusi akan pergerakan tukang atau bahan yan terlalu jauh dan memakan waktu yang lama. Dengan merubah dan mencoba coba dapat ditemukan sebuah alur yang baru yang nantinya akan menjadi acuan dalam pengambilan data waktu. Bagan alir penelitian dapat dilihat pada Gambar 1.

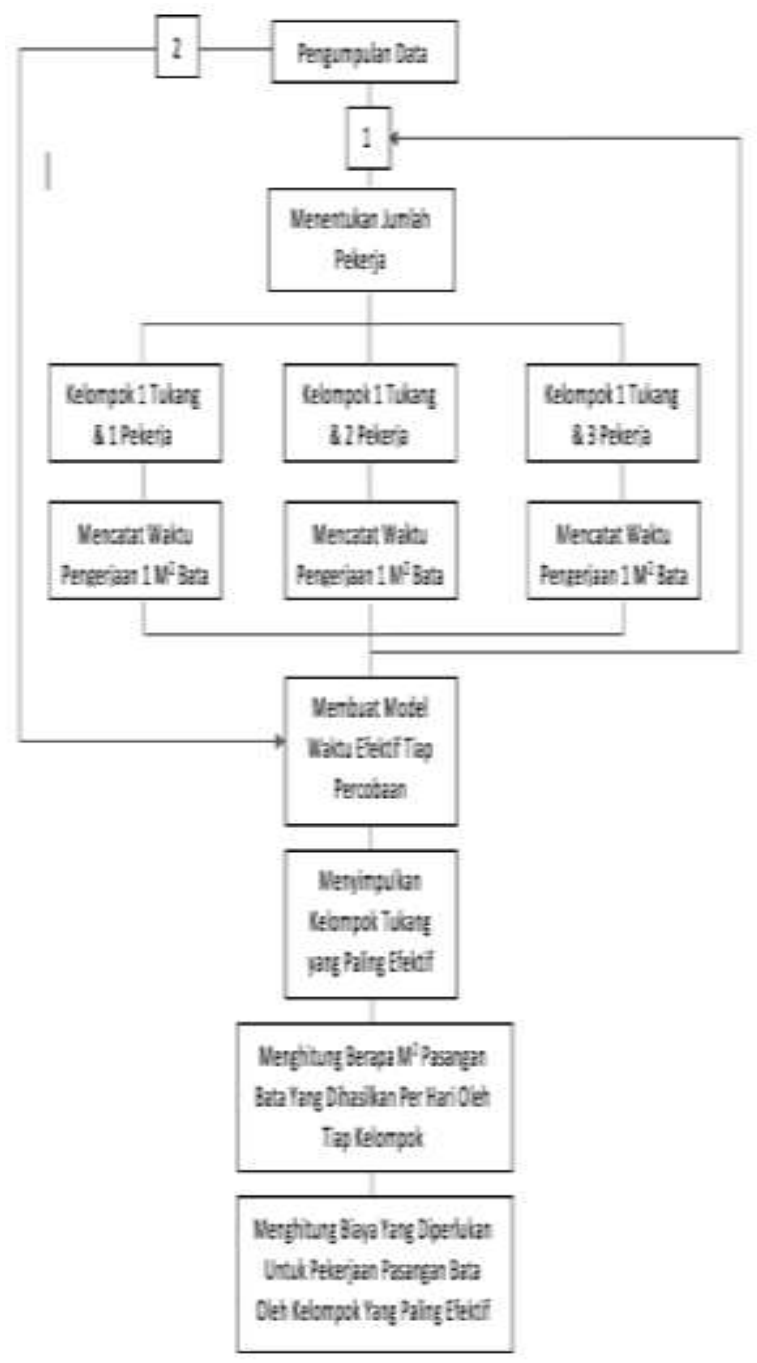

Gambar 1. Chart Pengambilan Data

\subsection{Pengambilan Data Waktu Lapangan Berdasarkan Flow Diagram Dan String Diagram}

Data di lapangan diambil sebanyak 9 kali per harinya dalam 7 hari sehingga terkumpul 63 data yang diambil dari penelitian di lapangan. Dari 63 data tersebut diambil rata-rata waktu yang dibutuhkan tiap kelompok pekerja untuk pengerjaan $1 \mathrm{~m}^{2}$ pasangan bata. Data tersebut diambil dari tiga kelompok pekerja yang masing - masing kelompoknya dihitung tiga kali per harinya dalam waktu yang berbeda (pagi, siang, dan sore) selama 7 hari. Pengambilan data per hari dilakukan dengan urutan sebagai berikut :

1. Kelompok 1 (1 Tukang \& 1 Pekerja) : Pukul 08.00, 10.00, 15.00 WIB

2. Kelompok 2 (1 Tukang \& 2 Pekerja) : Pukul 08.00, 10.00, 15.00 WIB

3. Kelompok 3 (1 Tukang \& 3 Pekerja) : Pukul 08.00, 10.00, 15.00 WIB

\subsection{Membuat Model Pekerjaan Dengan Metode Method Study}

Model adalah suatu permodelan yang dibuat berdasarkan waktu pekerjaan per siklus dan dirata - rata dengan siklus terpanjang sebagai pembaginya. Model ini dibagi menjadi 3 menurut kelompok pekerja yang terkait di dalamnya. Waktu menganggur (bagian yang diarsir) dari tiap - tiap model akan dibuang sehingga dihasilkan waktu yang dibutuhkan oleh masing - masing kelompok untuk mengerjakan 1 $\mathrm{m}^{2}$ pasangan bata.

Dengan mengetahui waktu yang dibutukan untuk pekerjaan $1 \mathrm{~m}^{2}$ bata, maka dapat ditentukan kelompok pekerja mana yang paling produktif. Efisiensi pekerja dilakukan dengan membandingkan siklus pekerjaan dengan siklus pekerjaan terpanjang sehingga ditemukan presentase efisien kerja.

Model pekerjaan digolongkan menjadi 3 bagian, yaitu Work, Task, dan Activity. Di mana Work yang dimaksudkan di sini adalah pekerjaan pasangan bata. Task adalah jenis / macam pekerjaan yang meliputi mengangkat alat \& bahan, mengaduk PC, dan memasang bata. Sedangkan Activity adalah penggolongan pekerjaan atau pembagian Task. Task dibagi berdasarkan komposisi jumlah pekeja dan keahlian pekerja. Dalam pekerjaan pasangan bata, seorang tukang hanya mengerjakan pemasangan bata saja, sedangkan pekerja melakukan pengangkatan alat \& bahan serta mengaduk mortar dengan adukan 1PC : 5PP. Jumlah atau volume adukan yang dibuat oleh pekerja mengikuti permintaan tukang dan pekerja harus menjaga agar tukang tidak kehabisan mortar sehingga pekerjaan dapat berlangsung dengan efisien.

Model pekerjaan dibuat dengan hasil waktu rata - rata tiap kelompok kerja dalam mengerjakan Activity yang ada. Waktu rata - rata yang dibutuhkan seorang pekerja untuk melakukan sebuah aktifitas tersebut menjadi acuan pembuatan model. Sehingga akan dihasilkan tiga buah model kerja sesuai dengan 
kelompok kerja yang ada, yaitu 1 tukang 1 pekerja, 1 tukang 2 pekerja, dan 1 tukang 3 pekerja.

\subsection{Biaya Pekerjaan Pasangan Bata Per $\mathbf{M}^{2}$ Menurut SNI Tahun 2008 dan di Lapangan}

Pada proyek Perumahan Nurasa Regency Nganjuk dipakai perbandingan adukan PC : PP sebesar $1: 4$. Dilihat dari koefisien SNI tersebut, maka untuk $1 \mathrm{~m}^{2}$ pasangan Bata dengan adukan PC : PP sebesar 1 : 4 didapat total harga $\mathrm{Rp}$ 86.472.50 dengan 1 tukang dan 2 pekerja. Dengan mengetahui volume satuan bahan, maka akan dihasilkan harga satuan pekerjaan pasangan bata untuk pekerjaan $1 \mathrm{~m}^{2}$ pasangan bata dengan komposisi pekerja 1 tukang dan 2 pekerja dan adukan 1PC : 4 PP.

\subsection{Data Perbandingan Biaya Pekerjaan Pasangan Bata Per Hari}

Volume pekerjaan pasangan bata per hari tergantung dari berapa banyak pekerja yang terlibat dalam pekerjaan pasangan bata tersebut. Dalam skripsi ini kita membahas pekerjaan bata yang dilakukan oleh 1 orang tukang dan 2 orang pekerja (pembantu tukang). Dalam menentukan jumlah tukang dan pekerja ini, telah dilakukan pengamatan lapangan dan pengolahan data dengan metode Method Study yang menunjukkan bahwa 1 orang tukang dan 2 orang pekerja adalah kelompok yang paling produktif.

Menurut kenyataan yang terjadi di lapangan, waktu kerja yang disediakan per hari adalah 8 jam yang dimulai pukul 07.00 WIB 16.00 WIB. Waktu kerja ini jelas berbeda dengan waktu kerja efektif menurut SNI, di mana waktu kerja efektif menurut SNI adalah 6 jam per hari. Hal ini dikarenakan oleh beberapa jenis pekerjaan yang diabaikan atau tidak dihitung dan tukang yang bermalas - malasan atau menggunakan jam kerja untuk keperluan pribadi sehingga waktu terbuang.

Beberapa jenis pekerjaan yang diabaikan atau tidak dihitung salah satunya adalah pekerjaan persiapan. Pekerjaan persiapan memang terlihat sepele namun memerlukan waktu yang relative banyak. Pekerjaan persiapan antara lainnya meliputi pemasangan andang / scaffolding, lot bata (pekerjaan benangan, sehingga bata dapat terpasang lurus dan rapi, penyiraman bata agar lebih mudah melekat pada PC (adukan semen), dan pembersihan lapangan.

Dengan mengabaikan beberapa jenis pekerjaan tersebut, maka waktu efektif di lapangan diperkirakan 6 jam per harinya.
Dengan waktu yang ada, maka dengan memakai kelompok kerja yang terdiri dari 1 orang tukang dan 2 orang pembantu tukang dapat dihasilkan \pm $12 \mathrm{~m}^{2}$ pasangan bata dalam waktu 1 hari kerja.

Melalui penelitian selama 3 hari kerja, dalam 1 hari kerja seorang tukang batu dan 2 orang pekerja dapat menghasilkan :

1. Hari pertama: $13,6 \mathrm{~m}^{2}$

2. Hari kedua $: 11,71 \mathrm{~m}^{2}$

3. Hari ketiga $: 12,14 \mathrm{~m}^{2}$

Maka rata - rata dalam 1 hari kerja, sebuah kelompok kerja yang produktif dapat menghasilkan $12,48 \mathrm{~m}^{2}$ pasangan bata.

Berdasarkan data yang diperoleh dari proyek, sebuah rumah type 45 di Nganjuk mempunyai luasan pasangan bata $124,55 \mathrm{~m}^{2}$. Apabila per hari dapat dihasilkan 12,48 $\mathrm{m}^{2}$ pasangan bata, maka pasangan bata untuk sebuah rumah type 45 dapat diselesaikan dalam waktu 9,977 hari $\approx 10$ hari kerja.

Perhitungan koefisien harian di lapangan didapat dengan membagi koefisien pasangan bata per $\mathrm{m}^{2}$ pasangan bata dengan 0.08013 . Hal ini dilakukan untuk membuat agar jumlah tukang dan pekerja dapat sesuai dengan satuannya, yaitu orang per hari. Rumus untuk memperoleh koefisien pasangan bata per hari adalah:

1. Batu Bata : $70 / 0.0813=873.6$ Buah

2. Pasir Pasang : $0.043 / 0.0813=0.5366 \mathrm{M}^{3}$

3. Semen : $11.5 / 0.0813=143.52 \mathrm{Kg}$

4. Tukang Batu : $0.0813 / 0.0813=1$ Orang per hari

5. Pekerja : $0.16026 / 0.0813=2$ Orang per hari

Perhitungan koefisien harian SNI didapat dengan membagi koefisien pasangan bata per $\mathrm{m}^{2}$ pasangan bata dengan 0.1. Hal ini dilakukan untuk membuat agar jumlah tukang dan pekerja dapat sesuai dengan satuannya, yaitu orang per hari. Rumus untuk memperoleh koefisien pasangan bata per hari adalah:

1. Batu Bata : $70 / 0.1=700$ Buah

2. Pasir Pasang : $0.043 / 0.1=0.43 \mathrm{M}^{3}$

3. Semen : $11.5 / 0.1=115 \mathrm{Kg}$

4. Tukang Batu : $0.1 / 0.1=1$ Orang per hari

5. Pekerja : $0.3 / 0.1=3$ Orang per hari

Dengan melihat RAB tersebut, dapat kita ketahui bahwa biaya per hari pekerjaan pasangan $1 / 2$ bata dengan komposisi pekerja 1 tukang dan 2 pekerja dan adukan 1PC : 4PP adalah Rp $965,896.80$ dan didapatkan $12.48 \mathrm{~m}^{2}$ pasangan bata. Sedangkan SNI membutuhkan biaya Rp $864,725.00$ per hari pada pekerjaan pasangan $1 / 2$ bata komposisi adukan 1PC : 4PP dan hanya didapatkan $10 \mathrm{~m}^{2}$ pasangan bata . 
Dengan mengatur komposisi pekerja menjadi kelompok kerja yang paling produktif, maka kita dapat melakukan penghematan biaya pada RAB. Penghematan biaya pekerja antara SNI dan lapangan di sini adalah Rp 101,171.80 per hari kerja dan selisih volume $2,48 \mathrm{~m}^{2}$.

\section{KESIMPULAN}

Penelitian dilakukan pada proyek rumah sederhana di Perumahan Nurasa Regency Kota Nganjuk. Penelitian biaya pekerjaan pasangan bata ini dilakukan dengan menggunakan metode Work Study. Hal yang ditinjau adalah pekerjaan pasangan bata per meter persegi dengan tiga kelompok tukang yang berbeda. Dari penelitian tersebut dapat disimpulkan:

1. Produktivitas kelompok kerja pada pekerjaan pasangan bata mempunyai produktivitas sebagai berikut :

a. 1 Tukang \&1 Pekerja : Tukang bekerja 100\% namun Pekerja hanya 55.8\%

b. 1 Tukang \& 2 Pekerja : Tukang 100\%, Pekerja1 82.99\%, Pekerja2 70,13\%

c. 1 Tukang \& 3 Pekerja : Tukang 100\%, Pekerja1 20.88\%, Pekerja2 35.42\%, Pekerja3 28.45\%

Sehingga didapatkan bahwa kelompok 1

Tukang dan 2 Pekerja adalah kelompok kerja yang paling produktif.

2. Didapatkan kelompok pekerja paling produktif dan paling murah dengan komposisi 1 Tukang dan 2 Pekerja. Hal ini dikarenakan presentase produktivitas tertinggi masing - masing pekerja didapatkan pada kelompok 1 tukang dan 2 pekerja, yaitu Tukang 100\%, Pekerja1 82,99\% , dan Pekerja2 70,13\%. Sedangkan harga pemasangan bata per meter persegi Rp $77,972.50$

3. Sebuah kelompok pekerja yang produktif dapat menghasilkan $\pm 12.48 \mathrm{~m}^{2}$ pasangan bata per harinya, di mana per hari kerja memakan waktu kerja 7 jam dan diasumsikan 1 jam sisanya adalah waktu istirahat dan waktu persiapan. Sedangkan kelompok kerja berdasarkan SNI dapat menghasilkan $10 \mathrm{~m}^{2}$ pasangan bata per hari.

4. Pekerjaan pasangan bata per $\mathrm{m}^{2}$ di lapangan oleh kelompok kerja paling produktif dengan mengabaikan kepala tukang, mandor, dan pekerjaan persiapan serta kebutuhan bahan yang mengacu pada SNI didapatkan biaya total sebesar Rp 77,972.50 sedangkan SNI membutuhkan Rp 86.472,50.

Selisih rencana anggaran biaya antara SNI dan metode Work Study per harinya adalah Rp 101,171.80 di mana biaya oleh SNI lebih mahal dibandingkan biaya dengan metode Work Study mengingat volume pasangan bata yang didapatkan per hari di lapangan adalah $12,48 \mathrm{~m}^{2}$ sedangkan SNI hanya $10 \mathrm{~m}^{2}$.

Setelah melakukan penelitian terhadap Rencana Anggaran Biaya (RAB) dengan metode Work Study dengan metode penelitian langsung di lapangan, penulis menyarankan hal - hal berikut: Untuk pelaksana proyek disarankan untuk pelaksana proyek untuk dapat menentukan jumlah perbandingan tukang dan pekerja dengan lebih teliti agar produktivitas terjaga dan biaya pekerjaan menjadi lebih murah. Untuk Akademisi disarankan kepada peneliti selanjutnya untuk lebih mendetailkan biaya material seperti semen ,pasir dll untuk dapat menambah wawasan bagi pembaca yang lainnya.

\section{DAFTAR PUSTAKA}

[1] Subarjo, Faktor-faktor yang mempengaruhi produktivitas karyawan pada CV. Granada, Jurnal Ekonomi dan Bisnis OptimuM, Vol. 5 No.2, 2015.

[2] Yuniarsih, Tjujtu dan Suwanto, Manajemen Sumber Daya Manusia, Alfabeta, Bandung, 2009.

[3] Rismayadi, Budi. Jurnal Manajemen dan Bisnis, Vol.1, No.1, 2015.

[4] Priyo, Mandiyo; Nasrudin, G. A. Jurnal Ilmiah Semesta Teknika, Vol.17, No.1, 2014.

[5] Izzhati, D. N. ; Anendra, Dhieka. Seminar Nasional Teknologi Informasi dan Komunikasi Terapan 2012. 2012.

[6] Rafian, A. M. ; Muhsin, Ahmad. Jurnal OPSI, Vol. 10, No. 1, Juni, 2017. 